\title{
ROBERT CAMPBELL
}

\section{What Makes a Five-Year Plan Feasible?}

Professor Hunter has shouldered a frightful burden in offering his critique of the growth strategy embodied in the First Five-Year Plan. The burden is not only in doing the study-fortunately he has the logic of the model and the power of the computer to help him there-but also in trying to convey in a simple way what his novel test consists of, why the plan was infeasible, and what some of the alternative paths for economic expansion were. He must have despaired of communicating these ideas without succumbing to the complexity of his model and becoming too technical, but it seems to me he has succeeded very well. In addition I find this a most stimulating paper, both for its substantive conclusions and as a way to look at some issues in Soviet economic history. Under pressure to condense and simplify, however, he has left a few points puzzlingly vague, and I would like both to expand on his explanation and to indicate what the puzzles are.

First, it does not come through clearly just why the plan was infeasible. There are two problems in what the Russians set out to do-a "gestationperiod" problem and a "structural change" problem, to which Professor Hunter refers at various points. The essence of these problems can be understood easily enough, if one is willing to countenance a little exotic biology. For the gestation-period problem, imagine an economy that produces nothing but eggs. The amount of eggs available for consumption over the future is governed by how the current egg output is used. Refraining from egg consumption today permits more eggs to be turned into chickens to produce more eggs for consumption in later periods. If the time it takes to go from egg to laying hen is short, big increases in egg output can be achieved rather quickly by relatively minor reductions in current egg consumption. But if it takes four years to hatch an egg and turn it into a laying hen, then the possibilities for raising egg output in the near term are quite limited. No matter how many eggs are sacrificed from consumption today, egg production for the next three years is beyond our control ; and even beyond that date the long gestation period makes it difficult to raise egg output rapidly.

For the structural problem, imagine an economy which produces both eggs and bacon, and in which pigs live on eggs. The planners want both $(a)$ to increase the output of bacon and eggs and $(b)$ to shift the proportions in which bacon and eggs are supplied for consumption toward more bacon. The possibilities are constrained just as before by how long it takes to turn eggs into 
laying hens and piglets into porkers. But the planners also face a new problem in this situation, associated with altering the mix toward more bacon in the breakfast ration. Suppose that pigs have a short maturity cycle; then holding back small shares of the maturing pigs for breeding purposes could lead to a very large bacon output soon, except that piglets can become porkers only by being fed on eggs. The limited ability of today's hen population to supply eggs both to feed pigs and to increase its own species to lay more eggs to feed more pigs in the future constrains how fast the planners can increase the output of bacon, even if they envisage relatively slow increases in the amount of eggs delivered for human consumption.

I gather from Professor Hunter's general description of his findings that he sees the infeasibility of the plan more in the gestation-period obstacles than in problems of structural rigidities. His alternative expansion paths for consumption suggest that conclusion, for example, since they show that the attainment of the goals was conditioned on particularly large consumption sacrifices in the first year, and that the early-year sacrifices are drastically eased by stretching out the plan period by even one year. This emphasis on the gestationperiod difficulties is related, however, to the fact that his input-output tables are quite highly aggregated, so that such real-world bottlenecks as the limited capacity of a specific branch within the industrial sector in the early yearssuch as machine-tool production, for example-are washed out. Also, examination of the input-output tables suggests that there was not a lot of structural change of the rising bacon-to-egg-ratio type. On the other hand, he says in one place that it would take a 9 percent cut in consumption in the first year to free enough resources to set the growth model in motion. That is difficult to understand, unless there existed some very serious structural bottleneck, especially when net investment was already 14 percent of national income in 1927/ 28 when the process started.

This question matters, because it is closely related to the question of why the planners produced such an infeasible plan. It would be easy to understand Gosplan's failure to recognize structural difficulties. They depend on a concatenation of interdependencies which the computer and linear programing can encompass, but which are rather opaque to the intuition and the schety. Bottlenecks are most directly revealed by the shadow prices that come out of the solution to the dual of the linear programing problem. Since Professor Hunter has not said much about bottlenecks reflected in shadow prices, I take it that they do not show up obviously. On the other hand, if the infeasibility of the plan results mostly from the fact that the gestation period for investment was too long for the new capacities to come on stream in time to deliver the intended output at the planned time, then that inconsistency would seem to be more easily discernible by relatively simple methods. A mere year-by-year sketch of 
investment programs, to be checked in one direction against total output of investment goods, and in the other with the required growth in capacities, would reveal that kind of inconsistency. There is in fact much detailed estimation of investment requirements in the Five-Year Plan document. But these estimates are developed in numerous pieces, and it may be that it is more difficult than it might appear to pull them all together, if one does not have in mind an input-output framework to organize what he is looking for. Probably more important in understanding the failure to make the plan consistent was that the economists in Gosplan were quickly learning at the end of the thirties not to ask questions about consistency. "Equilibrium" was not a word one could utter casually in the months when Stalin was urging Bolsheviks on to storm ever more redoubtable fortresses. It is worth recalling here that unbalanced planning has nothing to do with Marxian biases. Intersectoral balance is one of the prime features of Marx's scheme of expanded reproduction. The purging of the equilibrium concept from the economists' working ideas should be put down in the list of Stalin's crimes not only as a crime against economics but against Marxism as well.

A second issue that does not get neatly sorted out is the relation between two kinds of feasibility-we have been talking about the internal consistency of the plan, but there is also the question of the relation of the plan to the real world in terms of the assumptions about gestation periods, rates of retirement, changes in capital-output ratios, and so forth. There are conceivable gestation periods and changes in technology that would have made the plan internally consistent, and it was perhaps overoptimistic views on these matters that rationalized pushing the targets so high. And in the end, as Professor Hunter says, the underfulfillment of the plan was due to such extraneous factors as collectivization and world market developments as much as to the infeasibility of the plan. Even if the planners had made a plan that was feasible by his test, it would not have been fulfilled.

The most provocative theme in the article is the suggestion that there were alternative expansion paths that could have resulted in growth almost as good as that actually achieved, "with far less turbulence, waste, destruction, and sacrifice." That is a most important proposition if it can be demonstrated. It would be good counterfactual history, and would do for economic policy and the Stalinist economic development strategy in general what Barsov, Karcz, and Millar have done for the decision about collectivization. They have brought forward convincing evidence that peasant reluctance to meet the state's grain procurement hopes was not a political act that could only be countered by force but a result of the state's inept procurement policy, and that collectivization did not in fact succeed in extracting a surplus from agriculture to finance the investments of the First Five-Year Plan. As scholars we must be careful not 
to get emotionally committed in these old battles, but I for one would get great pleasure in seeing convincing proof that would vindicate the ideas of Bukharin and the other moderates about development strategy. Unfortunately I am not fully satisfied with the reasoning Professor Hunter offers for his conclusion. The intermediate steps in the argument are not fully developed, and there are some contradictory assertions that weaken the position: (1) He says in one place that in his test of the model, if consumption is constrained to grow at the same rate as population, then the output targets of the plan could not have been reached even within eight years. (2) Elsewhere he says that the purposes embodied in the plan could have been sought through consistent and plausible programs by adopting a stern no-growth, no-fall consumption policy (and he seems to imply they could more or less have been achieved). This relatively optimistic line is echoed in still another place where he says that if the planners had been willing to impose a 9 percent cut in consumption in the first year, then by 1934 they could have built capital stocks of 83 billion rubles, rising to 150 billion by 1936; this implies capital growth somewhat beyond what was called for in the plan. There is a big gap between these two perspectives on how easy it would have been to grow. In addition there seems to me to be an internal contradiction in his suggestion that if the Soviet planners had been willing to stretch out the growth process a bit longer and had planned for less consumption, they would have achieved the terminal goals of the First FiveYear Plan. The historical record is that they did keep consumption from growing, and indeed let it fall. But that implied that the original goals for sectoral output capacities and outputs were no longer relevant-the goals for housing and agricultural output did not need to be met for that kind of strategy, and indeed they were not. More important, I find it hard to uncover the direct link that tied the "waste, turbulence, sacrifice, and destruction" to the infeasibility of the plan. In the actual outcome the sacrifice in consumption made the attainment of the other goals feasible. Given the determination to grow, the infeasibility of the plan lay precisely in the consumption targets, as Professor Hunter shows very well. We cannot really get very far in relating experience to the plan or to the alternative scenarios, because we do not have reliable estimates of the actual course of consumption during these years.

Much of the sacrifice and waste resulted from action on variables that did not figure in the plan-the turning of the terms of trade against the Russians in the world market, and above all the consequences of collectivization. One can conceive of excessively ambitious plans causing misallocation of investment that tied up investment resources in the wrong places at the wrong times, but as I understand the linear programing model used to test the plan, it generates optimal expansion paths and so forecloses that kind of waste. It seems to me that the general climate of irrationality and arbitrary voluntarism that took 
over in this period, rather than infeasible ex ante plans, is the fundamental cause of the waste and sacrifice of the period. What the Soviet leaders did may have been misguided and wasteful, but it was feasible. After all, they did it.

Professor Hunter calls this an exercise in counterfactual history. The validity of that idea should not be made an issue of principle, but it does raise some interesting methodological questions that ought not to be overlooked, and I would like to conclude with some comments on them. Actually he does two quite different things. The first is to show that a particular view of the future was internally inconsistent, and hence "counterfactual" not only in the sense that it did not come to pass but that it could not have come to pass. The First Five-Year Plan was historical falsification ex ante! Second, he also undertakes to generate various scenarios that would not have had this defect in a search for alternatives that might have improved both on the plan and on what was actually accomplished under the inspiration of an infeasible plan. Economists tackle the issue of "what might have been" very boldly, armed with explicit models of how the world hangs together, and with nicely mechanical projection techniques. Whether others with a more general view of history should envy this stance or scoff at it is debatable. The great paradox of counterfactual history is that from any given point we can imagine many possible futures, but since only one eventuates, it is difficult to identify in what sense the others were possible. Professor Hunter solves that difficulty straightforwardly enough by seeing history as governed by policy-makers. The interest of what he then shows depends on how valid that assumption is. In this case, his description of what might have been is severely compromised by the impact on it of collectivization (a policy issue not reflected in his model) and the deterioration in the terms of trade caused by the world depression (a variable which was in the model, but outside the control of the policy-makers who thought they could create the future). Since the big strategic policy decisions of the First Five-Year Plan period included not only the plan itself but collectivization as well, one ought to insist on a model that includes that decision as a variable somehow. But even under that stricture, there is still considerable interest in seeing what the policy-makers might have effected if those disasters had not happened, since the actual historical argument about alternative futures took place before either of these catastrophes occurred. The most interesting counterscenario is the Bukharinite vision, and it is an interesting question to what extent the alternative expansion paths he describes can be identified with that vision. The device used for spinning the futures-linear programingrequires that all the policy variables be made either constraints or elements in the objective function. Two variants are explored. In one the question is, "If all the goals for terminal year output levels and structure are accepted, what 
were the implications for the trajectory of consumption in intermediate years over various horizons?" The other approach asks, "If various alternative trajectories for consumption are specified, how close could the economy have come to meeting the plan's targeted terminal output capacities over various periods of time?" These seem an inadequate proxy for the Bukharinite strategy, since if the planners had accepted a slower growth rate and some realistic constraints on consumption, then the terminal structure would have been different from what the Five-Year Plan planners sought. It would not have had so much housing or agricultural capacity, because consumption would have been smaller; and investment goods capacity would have been less important, because the investment rate would have been lower. In short, the linear programing mechanism has a wonderful power to generate alternative scenarios for ex post reflection, but it is important to make them historically relevant scenarios. 